samples reached almost $50 \%$. Isolated bacteria were mainly of faecal origin. The role of hygiene at semen collection is emphasized. As semen contamination may reduce fertility, periodical bacteriological examinations of semen are recommended.

\title{
Epididymal maturation of spermatozoa : effect on gamete quality
}

\author{
J.L. DACHEUX ${ }^{(1) *}$, M. PAQUIGNON ${ }^{(2)}$ \\ (1) C.N.R.S., Laboratoire de Physiologie Comparée, Faculté des Sciences, 37200 Tours. \\ (2) I.T.P.-M.N.E., 149, rue de Bercy, 75595 Paris Cedex 12. \\ * INRA, Station de Physiologie de la Reproduction, Monnaie, 37380 Monnaie.
}

The fertilizing capacity of spermatozoa develop during their transit through the epididymis. This organ possesses several functions located in well determined sites. Epididymal cells produce and secrete in the lumen of the tubule several compounds such as numerous specific proteins. They also concentrate substances such as carnitine. The role of this compound is still unknown but the increase in carnitine and acetylcarnitine concentration in spermatozoa is associated with an enhanced motility. This epithelium constitutes a barrier between blood circulation and the luminal content of the tubule so that spermatozoa bath in a fluid exhibiting a very specific composition. Spermatozoon maturation through epididymis is characterized by successive morphological and physiological changes affecting gametes in very precise regions of epididymis. Initiation of motility is related to the increase in the movement of flagellum during transit. The biochemical analysis of proteins from the surface of the spermatozoon membrane shows three major stages in gamete maturation : loss or masking effect of protein compounds on the surface of testicular spermatozoa and occurrence of transitory then definitive compounds characteristic of a fertilizing spermatozoon. The development of the epididymal function at puberty takes place progressively. Marked disorders in epididymal activity immediately lead to a reduced fertility of the animal. Small variations in the activity of this organ might probably cause differences in gamete quality between animals especially in their preservation capacity in the liquid or in the frozen state.

\section{Patterns of circulating LH, FSH, prolactin and $E_{2} 17 \beta$ in the gilt during the follicular phase of the oestrus cycle}

\author{
Armelle PRUNIER ${ }^{(1)}$, Sylvaine CAMOUS ${ }^{(2)}$, J.P. RAVAULT ${ }^{(3)}$, \\ Françoise MARTINAT-BOTTE ${ }^{(4)}$
}

(1) INRA, Station de Recherches Porcines, Saint-Gilles, 35590 L'Hermitage.

(2) INRA, Station de Physiologie animale, 78350 Jouy-en-Josas.

(3) INRA, Station de Physiologie de la Reproduction, Nouzilly, 37380 Monnaie.

(4) I.T.P.-M.N.E., 149, rue de Bercy, 75595 Paris Cedex 12.

Blood samples were taken from 5 cyclic gilts every 15 minutes for 108 hours between days 15 and 18 of the oestrus cycle. Plasma concentrations of LH (luteinizing hormone), FSH (follicle stimulating hormone) and PRL (prolactin) were measured in the jugular vein and those of $E_{2} 17 \beta$ (oestradiaol-17 $\beta$ ) in the utero-ovarian vein.

In the late follicular/early luteal phase (days 15 and 16), LH pulses were numerous and their frequency close to 1 per hour. This high secretion could be necessary to the preovulatory growth of follicles. PRL secretion was also high.

Thereafter, the basal level, frequency and amplitude of LH pulses decreased and remained low at least between -36 and -12 hours before the preovulatory LH surge. PRL and FSH concentrations also declined while those of $E_{2} 17 \beta$ increased considerably. This increase in $E_{2} 17 \beta$ levels probably induced the decline in the secretions of LH, FSH and PRL. 